\title{
Crise econômica e as políticas monetárias convencionais e não convencionais: um breve survey da literatura*
}

\author{
Economic crisis and conventional and unconventional monetary policies: \\ a brief survey of the literature
}

Paulo José Saraiva**

\begin{abstract}
Resumo: A crise financeira americana de 2007/08 gerou questionamentos ao arcabouço teórico e a recomendação de política econômica do Novo Consenso Macroeconômico. Dentre os diversos problemas identificados, destacou-se a incapacidade de o Banco Central Americano controlar as taxas de juros de longo prazo, bem como a ineficácia da orientação para a frente da política monetária. Senão de outro modo, a alternativa para enfrentar a recessão econômica e a deflação de ativos foi a utilização de políticas monetárias não convencionais. Contudo, a revisão do Novo Consenso vem relativizando a importância e eficácia dessas políticas, particularmente para os períodos de normalidade econômica. Nesse contexto, elaborou-se em um breve survey acerca das fundamentações das políticas monetárias convencionais e não convencionais.
\end{abstract}

Palavras-chave: Políticas monetárias não convencionais. Novo Consenso Macroeconômico. Crise Americana

\begin{abstract}
The recent US financial crisis has raised questions about the theoretical framework and the economic policy recommendation of the New Macroeconomic Consensus. Among the several problems identified were the inability of the Central Bank to control long-term interest rates, as well as the ineffectiveness of the forward orientation of monetary policy. Otherwise, the alternative to face the economic recession and the deflation of assets was the use of unconventional monetary policies. However, the revision of the New Consensus has made the importance and efficacy of these policies more relevant, particularly for periods of normalcy. In this context, a brief survey on the fundamentals of conventional and non-conventional monetary policies was elaborated.
\end{abstract}

Keywords: Unconventional monetary policies. New Consensus Macroeconomic. American Crisis

JEL Code: E43; E52; E58

\footnotetext{
* Submissão: 03/07/2019. Aprovação: 08/03/2020. DOI: http://dx.doi.org/10.5380/re.v41i76.67804.

*** Professor de Economia da Universidade Federal Rural do Rio de Janeiro (Campus Três Rios) e do Programa de Pós-Graduação em Economia Regional (PPGER/UFRRJ, Campus Seropédica). E-mail: pjsaraiva@terra.com.br. ORCID: 0000-0003-3414-7337.
} 


\section{Introdução}

A orientação do Novo Consenso Macroeconômico (NCM) em relação à condução da Política Monetária (PM), que antecede a recente crise financeira americana, foi apoiada na "divine coincidence", na qual se argumentava os benefícios do regime de metas de inflação (RMI) para a consecução da atividade econômica o mais próximo possível do produto potencial. Dentre os instrumentos clássicos de PM (recolhimento compulsório, redesconto de liquidez e operações de mercado aberto) para atingir o objetivo de uma inflação baixa e estável, a manipulação da taxa de juros de curto prazo tornou-se a principal referência. Esta passou a ser ajustada pela regra de Taylor ou alguma variante desta.

Por outro lado, os riscos desse instrumento eram atribuídos a situação de limite inferior igual a zero da taxa de juros de curto prazo, quando da utilização de uma meta de inflação muito baixa, dado que as reduções na taxa de juros rapidamente se aproximariam do limite. Caso tal situação ocorresse, era amplamente aceito pelo mainstream a proposição de que a autoridade monetária poderia continuar a conduzir a PM e sistematicamente afetar as taxas de juros de longo prazo por meio da orientação para frente da PM (forward policy guidance).

No entanto, a recente crise financeira americana demonstrou a fraqueza dos argumentos de que a PM adotada ao longo das últimas duas décadas promovera uma "grande moderação", bem como evidenciou que o ambiente econômico, relativamente estável, não protege a economia da instabilidade financeira e de seus efeitos sistêmicos sobre a atividade econômica, podendo inclusive ser uma das causas dessa instabilidade. Ela demonstrou ainda que as operações do Banco Central (BC) no mercado aberto (open-market) perdem a sua eficácia, antes mesmo da taxa de juros aproximar-se de zero (armadilha da liquidez) e de que a "forward policy guidance" não opera como um instrumento capaz de suprir a perda da taxa básica de curto prazo e influenciar as taxas de juros longo prazo.

Tal situação exigiu que o "Banco Central Americano" (FED), e pouco tempo depois os bancos centrais da Inglaterra, Japão e União Europeia, dentre outros, utilizassem um amplo conjunto de políticas monetárias "não juros", cunhadas como "políticas monetárias não convencionais" (PMNC). Como resultado, surgiram dúvidas acerca dos benefícios do RMI na redução da variabilidade do produto e da inflação, bem como na condução da PM. 
Senão de outro modo, criou-se um amplo debate no meio acadêmico, tendo os defensores do NCM argumentando em defesa das políticas monetárias convencionais (PMC) - taxa de juros e gestão de expectativas - que vinham sendo utilizadas até 2007. Estas deveriam permanecer para o período pós-crise. Contudo, em períodos de ruptura econômica, como observado ao longo da crise de 2007, o BC deveria utilizar as PMNC (sinalização e políticas de balanço) como instrumentos de reversão da tendência de recessão na atividade econômica.

Dessa forma, o presente artigo buscou uma breve resenha da literatura do NCM pré e pós crise americana acerca das medidas convencionais e não convencionais de PM, permitindo um contraponto entre elas. Para tanto, são apresentadas quatro sessões, além dessa introdução. Na segunda parte, discute-se as características e mecanismos de transmissão da PMC a partir do NCM. Na sequência, apresenta-se um panorama das PMNC, quais sejam políticas de balanço (crédito, quase débito, cambial e de reservas bancárias), além da política de sinalização. Na quarta seção são resenhadas as críticas da revisão do NCM ao conjunto de PMNC, além da argumentação dessa visão acerca da inadequação dessas medidas em relação aos períodos de normalidade. Conclui-se o artigo com algumas considerações críticas.

\section{Política monetária convencional e os canais de transmissão da PM segundo o NCM}

Inicialmente, torna-se importante ressaltar que a nova reconfiguração da PM, a partir do novo consenso macroeconômico, elimina a equação LM, substituindo-a pela regra de condução da PM, ou seja, pela regra de Taylor ${ }^{2}$. Nessa nova abordagem, a equação de equilíbrio no mercado monetário não é necessária para a determinação da produção, dos preços e da taxa de juros, tornando a oferta de moeda uma variável endógena e residual. No entanto, essa hipótese depende da

\footnotetext{
${ }^{2}$ A equação abaixo descreve a regra da PM (regra de Taylor) e relaciona positivamente a taxa de juros nominal de curto prazo (o instrumento de política monetária) com a taxa natural de juros real $\left(r^{*}\right)$, o hiato do produto defasado $\left(y_{t-1}-\bar{y}\right)$, as expectativas futuras de inflação $\left(E t\left(\pi_{t+1}\right)\right)$ e a taxa de inflação passada $\left(\pi_{t-1}\right)$. Dessa forma, a política monetária responde aos desvios do produto e da inflação, dado os objetivos de estabilidade de preços e do produto. Como resultado, o modelo do NCM implica que a política monetária é conduzida para estabelecer uma meta para a taxa básica de juros sem qualquer consideração sobre a taxa de crescimento da moeda. Os sinais esperados de cada termo são mostrados a seguir:

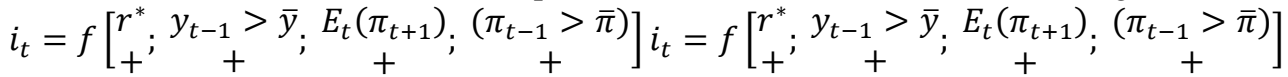


estabilidade da demanda por moeda para que a relação entre esta e a inflação seja estável no longo prazo. (MEYER, 2001; ROMER, 2000).

A orientação de $\mathrm{PM}$ a partir do $\mathrm{NCM}^{3}$ foi operacionalizada através do RMI desde a década de 1990 em diversas economias desenvolvidas e em desenvolvimento. Esta, caracteriza-se pela observação do Banco Central (BC) em relação às expectativas dos agentes de mercado, bem como da comunicação deste com o público, informando as suas perspectivas sobre o desempenho de variáveis macroeconômicas e as suas intenções de política econômica, buscando influenciar e ancorar as expectativas presentes e futuras de mercado. O canal de expectativas, incorporado pelo NCM, teve forte influência das expectativas racionais, tornandose uma meta intermediária da condução da PM.

De modo complementar, o canal da taxa básica de juros foi o mecanismo padrão dos modelos IS/LM, tornando-se a principal referência do modelo do NCM. Este, opera por meio da gestão de liquidez do BC no mercado interbancário (open-market) e, dado o poder de monopólio do BC em relação às reservas bancárias, não existia nenhuma dificuldade, em período de normalidade, na convergência da taxa de juros básica (overnight) à meta estabelecida para a taxa de juros de curto prazo (KUTTER; MOSSER, 2002). O canal de transmissão da taxa de juros de curto prazo tem sido o mecanismo de referência dos efeitos da PM sobre a substituição intertemporal, enfatizando as mudanças na taxa de juros de curto prazo e seus impactos sobre o consumo, o investimento, o produto e a inflação.

Partindo do modelo IS/LM, Taylor (1993, 1995) reafirmou ${ }^{4}$ que o canal de transmissão da taxa de juros é o principal mecanismo pelo qual a PM afeta a atividade econômica no curto prazo. Segundo o autor, dada a presença de rigidez de preços, as alterações na taxa de juros de curto prazo afetam as expectativas de mercado que por meio da teoria das expectativas da estrutura a termo da taxa de juros, alteram as taxas futuras de curto prazo e as taxas de juros de longo prazo. Esta última afetará as decisões intertemporais dos agentes, em relação ao

\footnotetext{
${ }^{3}$ Goodfriend e King (1997), Maccullum (1999), Clarida et al. (1999), Meyer (2001) e Goodfriend (2004).

${ }^{4}$ As mudanças na taxa de juros por meio das operações de mercado aberto, bem como a manipulação das expectativas de inflação por meio da "orientação para a frente da PM" deverão alterar a taxa de juros de longo prazo, impactando sobre as decisões intertemporais dos agentes e a demanda agregada da economia no curto prazo.
} 
investimento empresarial em capital e estoque, o investimento residencial e o consumo de bens duráveis.

O mecanismo de transmissão por meio do canal de expectativas de juros, conforme abordado na teoria de expectativa a termo da taxa de juros, é suposto reagir às mudanças na taxa de juros de curto prazo, afetando a formação de preços de bens e serviços por meio do impacto sobre as expectativas de inflação e desta sobre os salários nominais, além do efeito sobre a taxa de juros ex antes, alterando, desse modo, a inflação corrente e futura.

Nesse ponto, ressalta-se que Bernanke e Getler (1995) demonstraram que os efeitos da PM sobre a atividade econômica são maiores que as estimativas da elasticidade-juros do consumo e do investimento, implicando que a PM é transmitida por diferentes mecanismos. Além do canal padrão reestruturado por Taylor (1993, 1995), outros canais foram revistos e propostos pelos Novos Keynesianos, como pode-se observar em Mishkin (1995). Estes compreendem os canais de câmbio, crédito, portfólio e monetarista e descrevem os efeitos da PM nas decisões de balanço dos agentes, embora não tenham sido introduzidos formalmente nos modelos do NCM, segundo Goodfriend (2005) e Meyer (2001).

\section{Figura 1 - Mecanismos tradicionais de transmissão da política monetária}

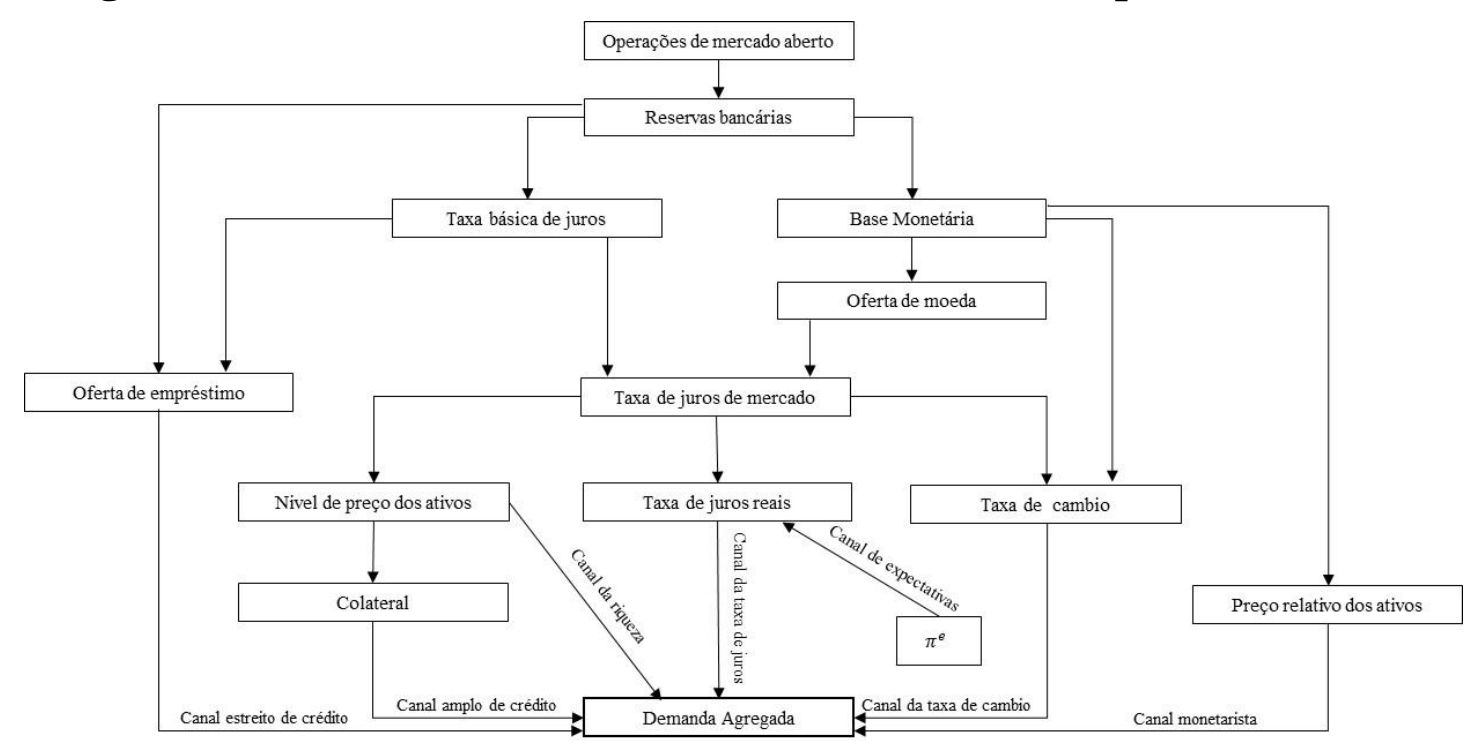

Fonte: Kutter e Mosser (2002). 
Ressalta-se, a partir da Figura 1, que os diversos canais implicam em diferentes mecanismos de transmissão da PM que não são mutuamente exclusivos, sendo acionados pelas operações do BC no mercado aberto, alterando o volume de reservas do sistema bancário e, por conseguinte, a taxa básica de juros e a base monetária. O seu efeito se difunde pelo crédito, preço de ativos, taxa de câmbio, taxa real de juros, além das expectativas de mercado em relação às taxas futuras de juros e a inflação, impactando sobre a demanda agregada. Contudo, o $\mathrm{NCM}^{5}$ simplificou os efeitos da taxa de juros de curto prazo às taxas longas e suas implicações nas decisões intertemporais de gasto e poupança, supondo que a taxa básica representa um índice de condições globais, que determina de forma estável e previsível os demais canais, uma alusão direta à hipótese de mercados eficientes.

\section{Crise financeira e a política monetária não convencional}

Durante a crise financeira americana iniciada em 2007, observou-se que a PM, bem como os mecanismos tradicionais de transmissão desta, não funcionaram adequadamente. Tal fato deveu-se, entre outros fatores, à excessiva volatilidade na demanda por reservas e redução dos empréstimos de liquidez entre as instituições depositárias, assim como a interrupção de crédito em diversos segmentos do mercado financeiro, limitando a capacidade do BC de controlar a taxa de juros de longo prazo e impedindo a transmissão da PM sobre os demais canais (CECIONI et al. 2012). Tal situação foi agravada, quando a taxa de juros de curto prazo se aproximou do limite inferior igual a zero (armadilha da liquidez ${ }^{6}$ ). Nessa circunstância, a PMC perde totalmente a sua eficácia, sendo a alternativa a utilização de PMNC, também identificadas como políticas de balanço e de sinalização, sendo que nessa segunda a autoridade monetária expande o seu balancete, como observado a partir de meados de 2007 nos EUA e nos anos seguintes na Inglaterra, Japão e União Europeia. Segundo Borio e Disyatat (2009, p. 1), essas políticas apresentam características específicas, que as distinguem da PM convencionais adotadas ao longo das últimas décadas:

\footnotetext{
${ }^{5}$ Uma característica do NCM refere-se ao fato de que a regra de Taylor desconsidera os efeitos da taxa de juros sobre outros canais de transmissão da PM, representados pelo efeito da moeda sobre os gastos, nos ativos financeiros e na taxa de câmbio. (GOODFRIEND, 2005; MEYER, 2001).

${ }^{6}$ Segundo Taylor (2010) e Blinder (2010), o FED iniciou as políticas não convencionais quando as taxas de juros estavam em $2 \%$ a.a. Senão de outro modo, os EUA já haviam entrado na armadilha da liquidez, muito antes das taxas de juros chegarem a $0-0,25 \%$ a.a.
} 
It is the specific market segment chosen as the focus of central bank operations that is, for the most part, novel - at least by recent experience. Moreover, rather paradoxically, some of these policies would have been regarded as "canonical" in academic work on the transmission mechanism of monetary policy done in the 1960s-1970s, given its emphasis on changes in the composition of private sector balance sheets.

Uma distinção das PMNC abordadas por Borio e Disyatat (2009) se refere à dissociação entre a gestão de liquidez (políticas de juros) e de balanço. Esta última pode ser operacionalizada de forma independente, uma vez que o BC dispõe de instrumentos que impeçam qualquer efeito sobre a taxa de juros de curto prazo. Ressalta-se que tais políticas objetivam influenciar o balanço do setor privado e/ou as expectativas, embora o $\mathrm{BC}$ não detenha monopólio sobre as decisões privadas, como tem sobre as reservas bancárias. Ademais, essas medidas representam riscos financeiros, que são absorvidos pelo $\mathrm{BC}$ na medida em que alteram a composição de seu balancete. Na Figura 2, os canais de transmissão das políticas monetárias não convencionais são sintetizados e na sequência, cada uma destas políticas é analisada.

Do ponto de vista teórico, as PMNC fundamentam-se em dois canais de transmissão. No primeiro, denominado de canal de sinalização (signaling channel), a comunicação do $\mathrm{BC}$ com os agentes econômicos busca restaurar a confiança dos mercados e ancorar as expectativas dos agentes em relação aos rumos das políticas econômicas. Embora esse canal tenha sido evidenciado como uma meta intermediária na condução da PM convencional pelo NCM, ele é tido como um importante instrumento de apoio às políticas de balanço, na medida em que a informação ao público acerca das intenções da autoridade monetária tende a reduzir a incerteza e melhorar os efeitos das políticas não convencionais (CECIONI et al., 2012; BÓRIO; DISYATAT, 2009). Segundo Yellen (2011a), observou-se que as taxas de juros de longo prazo dos títulos do tesouro reagiram aos anúncios de compra desses ativos pelo FED, antes mesmo das primeiras compras.

O segundo é o canal de balanço, similar ao apresentado na Figura 1. Porém, em períodos de ruptura financeira, na qual a taxa de juros se aproxima de zero, o $\mathrm{BC}$ tem que operar a PM diretamente, por meio de outros instrumentos que não o open market. Os principais instrumentos são a provisão de liquidez às instituições 
depositárias e não depositárias, a compra de títulos públicos e privados diretamente nos seus respectivos mercados, a concessão de crédito às instituições financeiras e não financeiras e as operações envolvendo variações nas reservas compulsórias, bem como da realização de operações cambiais. A justificativa para essas medidas decorre de o fato de que os ativos e passivos das instituições privadas não são perfeitamente substituíveis, principalmente em períodos de ruptura financeira, gerando tensões e paralizações em determinados segmentos do mercado financeiro, além de fricções nas condições de financiamento de uma economia (CECIONI et al., 2012).

\section{Figura 2 - Canais de transmissão das políticas monetárias não} convencionais

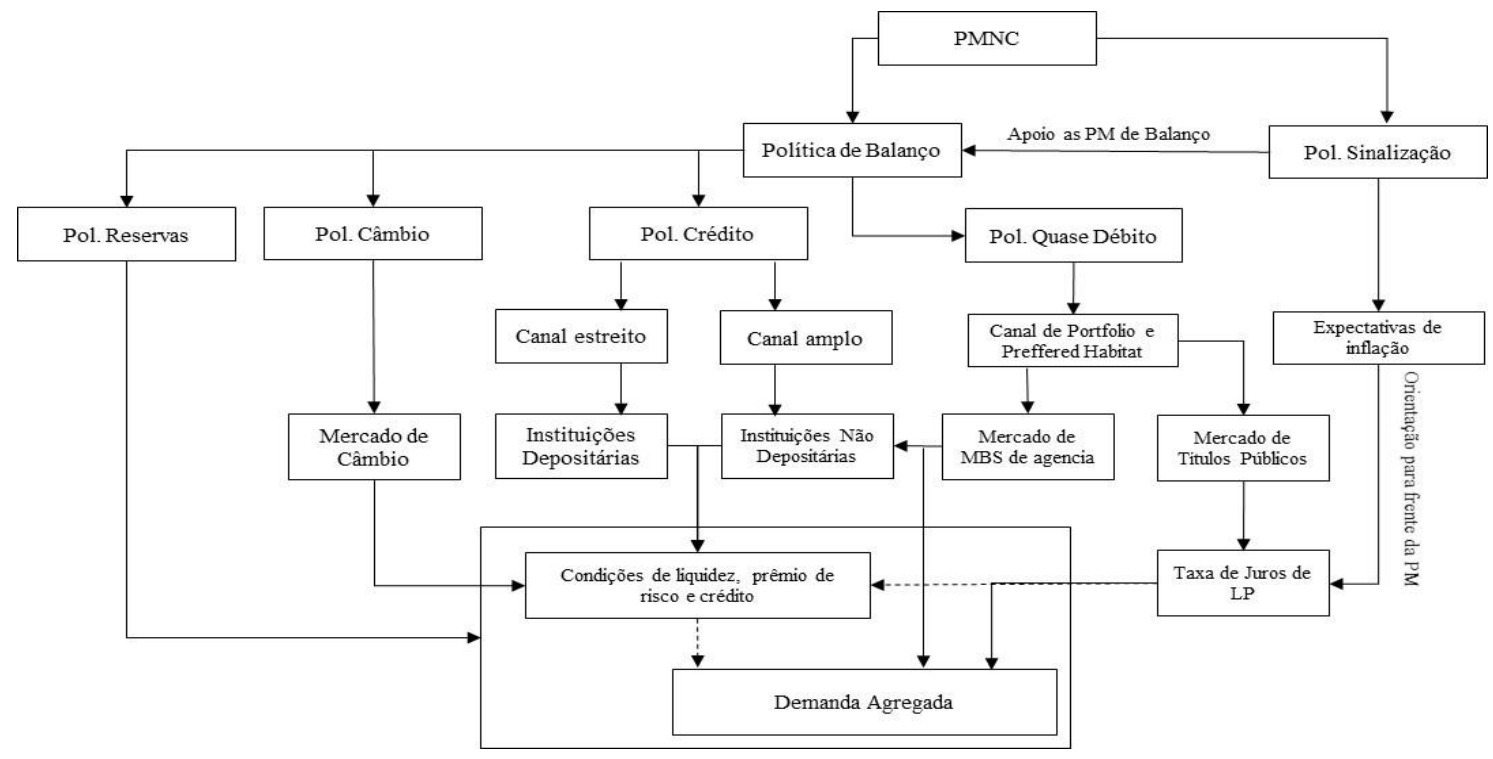

Fonte: elaboração própria.

\subsection{Canal de sinalização}

O canal de sinalização utiliza a comunicação com o público, de modo a informar as suas intenções da autoridade monetária em relação às PM a serem adotadas, sejam elas destinadas à taxa de juros de longo prazo, à compra de ativos financeiros ou relacionadas a outras medidas, sendo que a sua eficácia depende da credibilidade da autoridade monetária e de que a expectativa e a confiança do mercado afetem as condições financeiras e macroeconômicas. No entanto, nem toda política de comunicação deve ser entendida como PMNC. Segundo Cecioni et al. (2012, p. 16): "Thus, communication should be considered an 
unconventional tool of monetary policy only when it is used by a central bank to convey information or pursue objectives that go beyond its standard practice".

Observa-se que até a crise de 2007 era amplamente aceita a hipótese no NCM, de que em uma situação de a taxa de juros de curto prazo ser próxima a zero, o BC permaneceria influenciando as taxas longas por meio de expectativas da estrutura a termos da taxa de juros, gerenciando as expectativas por meio da "orientação para frente" da PM (foward policy guidance). Segundo Eggertsson e Woodford (2003), as políticas de expansão quantitativas só teriam efeito através do canal de sinalização. Tal fato se deve à suposição do NCM a respeito da inexistência de fricções de financeiras ${ }^{7}$ cujas implicações são de que as mudanças no balanço do BC não afetam o comportamento dos agentes e desse modo são irrelevantes para o balanço do setor privado.

Nessa perspectiva, Eggertsson e Woodford (2003) defenderam que o canal de sinalização é o único instrumento eficiente em períodos de crise financeira, dado que as expectativas sobre a trajetória das taxas de juros influenciam as decisões das empresas e das famílias. Para tanto, o BC deveria definir um critério objetivo $^{8}$ para a condução de $\mathrm{PM}$, em substituição à meta de inflação e seguir o "princípio da irresponsabilidade", mantendo a taxa de juros próxima a zero durante um determinado período, além de permitir que os preços se elevassem, promovendo dessa forma expectativas inflacionárias. Segundo Eggertsson e Woodford (2003, p. 43):

It can be verified that this rule does indeed achieve the optimal commitment solution. If the price-level target is not reached, because of the zero bound, the central bank increases its target for the next period. This, in turn, increases inflation expectations further in the trap, which is exactly what is needed to reduce the real interest rate.

\subsection{Canal de balanço}

Quando a taxa de juros de política torna-se próxima a zero, os mecanismos de transmissão via canal de taxa de juros perdem o seu efeito e o BC perde a

\footnotetext{
7 Segundo Joyce et al. (2010), na presença de fricções financeiras, mercados incompletos e substitutibilidade imperfeita entre os ativos, as políticas de expansão quantitativa podem exercer mudanças diretas nos preços dos ativos, alterando a oferta relativa de diferentes de ativos e induzindo os agentes a reestruturar as carteiras.

${ }^{8}$ Eggertsson e Woodford (2003) definem uma regra de condução da política monetária ótima, quando a taxa de juros de curto prazo é zero. Nesse modelo, $\widetilde{P}_{t}=P_{t}+\lambda / K x_{t}$, o critério objetivo $\left(\tilde{P}_{t}\right)$ depende de um índice de preços $\left(P_{t}\right)$ mais o hiato do produto $\left(x_{t}\right)$ multiplicado pelo coeficiente $(\lambda / K)$, que reflete o peso relativo do hiato do produto em relação à estabilidade do produto.
} 
capacidade de reduzir os spreads de juros de longo prazo, uma vez que ele não consegue achatar a estrutura a termo da taxa de juros e o prêmio de risco, e dessa forma, o BC perde a capacidade de estimular a demanda agregada e produto. Ademais, os canais de crédito, de câmbio, de preços dos ativos e dos preços relativos deixam de operar via taxa básica, limitando ainda mais a PM. Como alternativa, a adoção de PMNC representa um conjunto de instrumentos de intervenção direta do $\mathrm{BC}$ em mercados financeiros específicos, capazes de reverter o círculo vicioso de uma potencial recessão e deflação de ativos (BLINDER, 2010).

Segundo Borio e Disyatat (2009), as PMNC, também denominadas políticas de balanço (balance sheet policy), podem ser subdivididas em quatro categorias: i) política de câmbio, ii) política de gerenciamento de quase débito, iii) política de crédito; e iv) política de reservas bancárias. No quadro 1, apresentam-se as tipologias de políticas de balanço, bem como os principais impactos esperados dessas políticas na estrutura do balanço do setor privado:

\section{Quadro 1 - Tipologia de políticas de balanço}

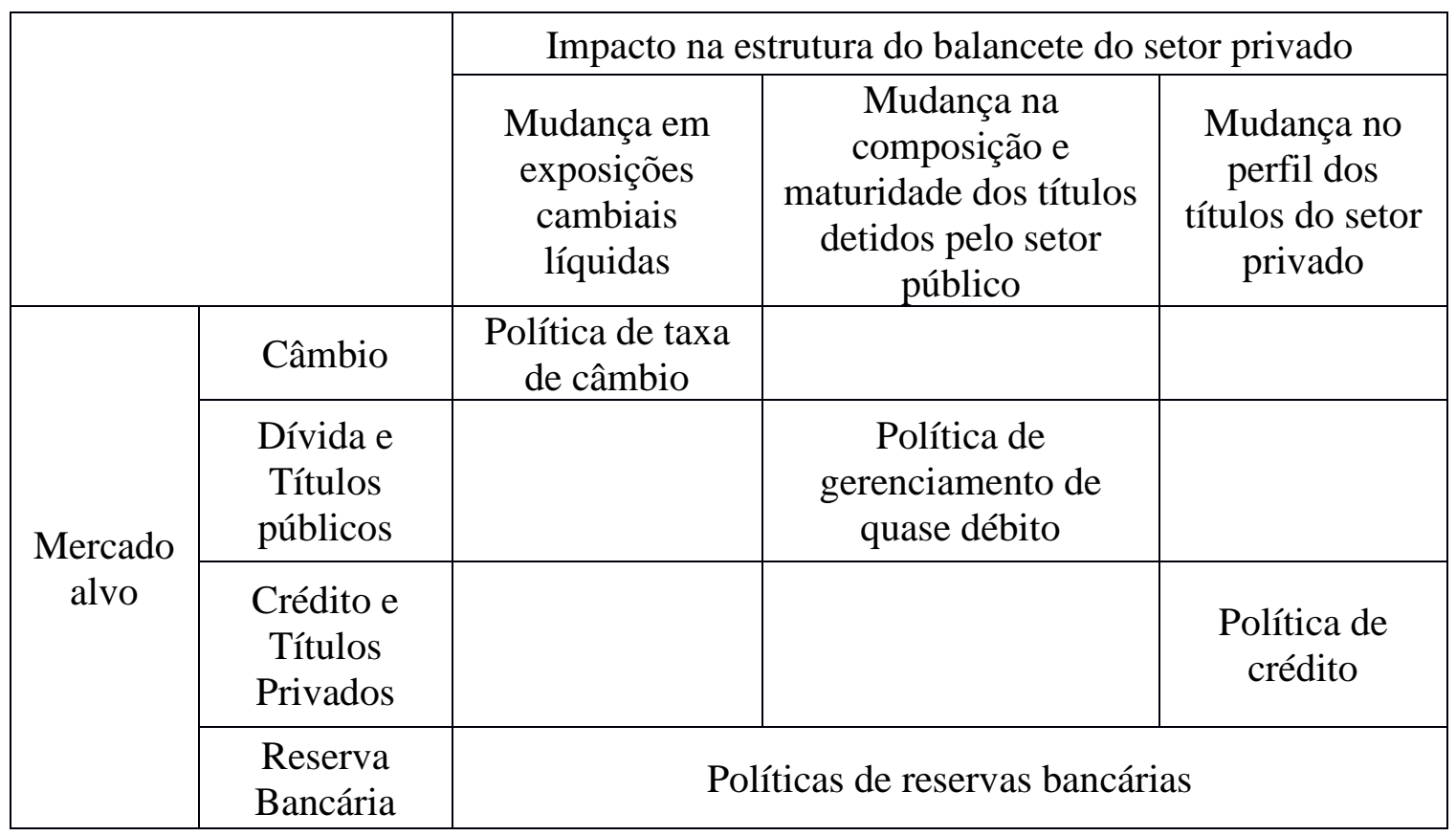

Fonte: Borio e Disyatat (2009, p. 7).

A partir do quadro 1, observa-se que cada uma dessas políticas de balanço do BC apresentam uma contrapartida em relação ao balanço do setor privado, 
sendo as principais características listadas a seguir, utilizando para tanto a referência de Borio e Disyatat (2009):

i. A política cambial é operada diretamente no mercado divisas estrangeiras e representa a intermediação direta do BC entre o mercado doméstico e o setor externo. Essas medidas buscam melhorar as condições de liquidez doméstica, reduzindo o risco de exposição do setor privado doméstico às variações abruptas na taxa de câmbio. Nessa política, o BC opera no mercado cambial (compra/venda de divisas estrangeiras, contratos de swap cambial e ampliação de garantias e contrapartidas), promovendo a diminuição de volatilidade e influência o preço da moeda estrangeira, para um dado nível da taxa de juros. Durante o episódio recente da crise financeira, o FED promoveu acordos de swap cambial, denominados de Reciprocal Currency Agreements (RCA) ${ }^{9}$ com diversos $\mathrm{BC}^{\prime}$ 's, de modo a permitir que essas instituições pudessem realizar operações domésticas de câmbio na moeda americana. Ademais, "exchange rate policy has been undertaken in a number of emerging market countries. This was done partly to counter abrupt reversals of capital inflows and the subsequent downward pressure on the exchange rate (for example, Brazil, Hungary and Mexico)" (BORIO; DISYATAT, 2009, p. 11).

ii. As políticas de gestão de quase débito (compra de títulos do governo ou troca de títulos de longo prazo por curto prazo) representam uma intermediação do BC entre o governo e o setor privado. Essas medidas buscam reduzir o prêmio de risco em relação a prazo e liquidez, dos títulos públicos em poder do mercado, promovendo a estabilidade do produto. A sua operacionalização ocorre por meio de compra de títulos públicos, inclusive títulos de agência pelo BC, podendo ser financiado por meio de variação da base monetária, ou com recursos das reservas bancárias. Ressalta-se que esses ativos são uma importante referência para o mercado, na medida em correspondem a uma taxa de benchmark (risk free), e desse modo, afetam os custos de financiamento e o preço dos ativos em geral. A efetividade dessa política de balanço exige, normalmente, um o grande volume de compras para que se tenha um efeito sobre o rendimento destes títulos ${ }^{10}$.

\footnotetext{
9 Os contratos de swap com Bancos Centrais de diversos países, denominado Reciprocal Currency Agreements (RCA) representaram o fornecimento excepcional de liquidez (dólares) aos bancos centrais estrangeiros para que esses pudessem prover liquidez em moeda americana nos seus respectivos mercados. Os países foram: Banco do México, Bank of England, Bank of Japan, Danmarks National bank, European Central Bank, Norges Bank, Reserve Bank of Australia, Bank of Corea, Sveriges Riksbank e Swiss National Bank.

${ }^{10}$ Segundo Borio e Disyatat (2009, p. 15), "Given the close substitutability between central bank and government liabilities, the portfolio balance effects may not be that large. Clouse et al. (2000) and Reinhart
} 
iii. A política de crédito atua sobre segmentos específicos do mercado financeiro (mercado interbancário e mercado não bancário), alterando a composição do balanço do setor privado, de modo a afetar as condições de financiamento. As operações realizadas pelo BC, que impactam sobre as dívidas privadas e valores mobiliários, alteram o seu balancete e se processa de várias formas, como alterações de colaterais e prazos de maturidade, contraparte em operações monetárias, empréstimos e aquisições de títulos privados. O objetivo principal é reduzir as tensões do mercado interbancário, em particular os prazos e spread, bem como melhoria das condições de crédito ao setor não bancário. Ressalta-se que tal política pode gerar efeitos indiretos, na medida em que o mercado em que atua desempenha um papel importante na intermediação financeira. Destaca-se ainda que essas medidas são realizadas diretamente com os intermediários financeiros, o que sugere indiretamente melhorias gerais no mercado, em virtude do papel desempenhado por essas instituições. Porém em mercados específicos $^{11}$, o BC realiza operações de intermediação direta, sem a participação das instituições depositárias, interpondo-se entre investidores e prestatários.

iv. A política de reservas bancárias utiliza-se do sistema bancário como um canal, fixando uma meta para as reservas, independente da forma como está é contrabalançada no ativo do BC, podendo ser em moeda estrangeira ou moeda doméstica. As mudanças no tamanho e composição dos ativos das instituições depositárias poderão impactar sobre os custos, o crédito, os rendimentos e os preços dos demais ativos, dependendo da aversão ao risco dessas instituições. Ademais, o impacto sobre o balanço do setor privado não é determinado e dependerá também da contrapartida em relação ao ativo no balanço do BC, quando da expansão das reservas. Ressalta-se que o Banco da Inglaterra reintroduziu esse mecanismo com a crise de 2007, e segundo (BÓRIO; DISYATAT, 2009, p. 11):

(t)he instruments of monetary policy shifted towards the quantity of money provided rather than its price (Bank Rate)" (Bank of England (2009). While bank reserves have also increased at other central banks, including the Federal Reserve, the ECB and the Swiss National Bank, this was simply the by-product of operations on the asset side. The

and Sack (2000), for instance, provide evidence that even sizeable changes in the composition of the public's asset holdings would have only small effects on yields. Thus, to impart sign effect on yields, the volume of transactions may have to be quite large.

11 "With the ABCP Money Market Fund Liquidity Facility (AMLF) (...) the Fed provided short-term loans to depository institutions to finance purchases of high-quality ABCP from money market mutual funds, thus sustaining their prices by avoiding fire sales. A similar objective was pursued with the Commercial Paper Funding Facility (CPFF) (...), which provided a temporary liquidity backstop to issuers of commercial paper and was intended, in particular, to reduce investors' and borrowers' concerns about "roll-over risk" (CECIONI, 2011, p. 13). 
increases were not seen to have any particular significance and, as such, do not constitute bank reserves policy.

Definidos os elementos conceituais das políticas de balanço, a abordagem teórica sobre o tema pode ser subdividida em três grupos. O primeiro enfoca os efeitos da PM sobre o preço de ativos e a substitutibilidade imperfeita no lado do ativo do balanço do setor privado, sendo referida como "canal de ajuste de carteira". A atuação do BC na compra de ativos da carteira do setor privado, normalmente títulos públicos e de agências governamentais, altera a oferta nesses mercados, promovendo uma redistribuição mais equitativa nos rendimentos relativos e no prazo de maturidade destes títulos. As referências são Tobin (1969), Ando e Modigliani (1963) e Modigliani e Sutch (1966).

A segunda vertente enfatiza a substitutibilidade imperfeita no lado do passivo do balanço do setor privado, sendo normalmente este referido na discussão do "canal de crédito". Nessas operações, o BC supre diretamente a demanda por empréstimos, além de oferecer condições mais atraentes (taxa de juros e prazo), objetivando a melhora nas condições de financiamento do mercado, induzindo o aumento do crédito e a melhoria nos preços de ativos. Os principais autores são Bernanke e Blinder (1989) e Bernanke e Gertler (1995).

Embora os canais de transmissão do lado do ativo e passivo sejam, respectivamente, a referência para as políticas de gestão de quase débito e de crédito, esses dois apresentam forte interação. A compra e troca de ativos (títulos do governo) em grande escala, além do aceite destes como garantias para empréstimos pelo $\mathrm{BC}$, opera como uma melhora nas condições de liquidez do mercado ao tornar mais líquida a carteira das instituições financeiras. De modo complementar, as operações de empréstimos do BC que absorvem os títulos mais arriscados da carteira dos bancos reduzem a necessidade dessas instituições de venderem esses ativos em condições desfavoráveis (preço em queda) para cobrir as exigências de capital. Segundo Borio e Disyatat (2009, p. 14), "[t]he combination of stronger balance sheets, higher collateral values and higher net worth, may help loosen credit constraints, lower external finance premia and revive private sector intermediation".

Por outro lado, essas políticas de balanço podem impactar de forma negativa sobre o risco de mercado, como enfatizado pelo canal de elevação de risco (risk- 
taking channel). Este identifica os impactos das PM, convencionais e não convencionais, sobre o grau de aversão e tolerância ao risco dos agentes. Nesse canal, observa-se que as PM que melhoram as condições de financiamento e promovem a redução dos riscos de portfólio dos agentes, por meio da redução de taxa de juros e compra de ativos específicos, podem gerar efeitos não desejados de aumento da exposição ao risco do sistema financeiro. Uma referência para essa discussão é apresentada por Borio e Zhu (2008).

\subsection{Canais de assunção de risco (risk-taking channel)}

O canal de risco opera na contramão dos outros canais de juros e de balanço, na medida em que uma taxa de juros mais baixa, bem como a melhoria das condições de financiamento e liquidez, promovida pelas PMC ou PMNC pode gerar uma tendência de elevação de crédito e maior exposição ao risco por parte dos participantes de mercado. Nessa proposição, as mudanças nas taxas de juros, associadas à função de reação do BC, podem influenciar a assunção de risco, na medida em que alteração na percepção e tolerância ao risco dos agentes de mercado. Segundo Borio e Zhu (2008, p. 2), "especially as its prominence is likely to have increased in the wake of financial liberalization and innovation and of changes in prudential frameworks".

Três mecanismos podem ser destacados, relacionados ao impacto comportamental dos agentes, o efeito renda e valorização de ativos, enquanto o terceiro interage com o canal de sinalização. No primeiro, apresentado por Rajan (2005) apud Mishkin (2012), baixas taxas de juros podem incentivar os gestores de ativos de instituições financeiras a buscarem alternativas de investimentos mais lucrativas, porém mais arriscados. Tais incentivos derivam da existência de contratos de desempenho firmados entre os gestores e as instituições financeiras em relação à performance dos portfólios, exigências de investidores, bem como de aspectos comportamentais.

Um segundo argumento, apresentado por Adrian et al. (2010), ressalta os efeitos desse canal sobre a renda e a valorização de ativos. As taxas de juros mais baixas podem elevar o valor das empresas, bem como de suas garantias (patrimônio líquido), estimulando uma maior alavancagem e consequentemente um nível maior de exposição ao risco. Como resultado "monetary policy affects risk appetite by changing the ability of intermediaries to leverage their capital 
(Adrian et al., 2010, p. 1). Nessa perspectiva, situações de rupturas financeiras geram impactos significativos nos credores.

O terceiro analisa as PM a partir da transparência, comunicação e credibilidade do BC em relação a sua função de reação. Nesse canal, quanto maior o grau de compromisso e transparência da autoridade monetária, maior será a capacidade de esta reduzir as incertezas e o prêmio de risco de mercado, promovendo uma percepção generalizada de um ambiente de negócios mais estável, inclusive para o futuro e consequentemente poderia estimular uma ampliação dos riscos assumidos pelos agentes. Segundo Borio e Zhu (2008, p. 10): "Casual observation would suggest that the risk-taking channel deserves closer exploration. Clearly, its possible presence is more easily visible to the naked eye in business fluctuations where background conditions are more extreme".

Finalmente, Borio e Zhu (2008, p. 10) argumentam que os três canais podem ser avaliados a partir do crescimento da atividade econômica global, iniciada em 2002, na qual coexistiam baixas taxas de juros ao mesmo tempo em que a volatilidade e os preços de ativos eram elevados. Nesse ambiente, foi verificou uma "busca por rendimentos", de modo a compensar as baixas taxas de juros. Ademais “market participants' reference to anticipations of a central bank easing of policy in the face of financial disruptions as a factor supporting risk-taking provides some indirect evidence of the empirical relevance of an insurance effect".

\section{Críticas do mainstream as PMNC em períodos de "normalidade" econômica}

Em períodos de normalidade, a autoridade monetária deverá conduzir a PM por meio da gestão de liquidez (taxa de juros de curto prazo), retornando a sua preocupação com as metas de inflação, porém, em situações de crise financeira, as PMNC são mais apropriadas. Na medida em que o funcionamento e os riscos de mercado tenham sido corrigidos e a atividade econômica tenha se recuperado, a PM deverá retornar a sua preocupação para o RMI (MISHKIN, 2010). Segundo Mishkin (2010, p. 245), "[t]he monetary policy that is appropriate during an episode of financial market disruption is likely to be quite different than in times of normal market functioning".

Tal proposição é reforçada por Woodford (2012), que questiona a eficácia das PMNC, particularmente as políticas de gestão de quase débito, afetarem as 
taxas de juros de longo prazo em períodos normais. Segundo o autor, quando os mercados operam de forma normal, essas medidas tendem a afetar as expectativas em relação às políticas futuras e não os spreads de taxa de juros. Nesse caso, as políticas de sinalização, que afetarem as expectativas dos agentes, alteram as taxas de longo prazo, sendo inclusive um importante instrumento de PMNC em períodos de exceção.

Ademais Bernanke (2012b), identifica a importância das PMNC em períodos de crise no reestabelecimento da liquidez dos mercados e estímulo à atividade econômica, sendo que estas operam de modo semelhante aos canais utilizados pelas políticas convencionais. No entanto, observa-se que, em períodos de exceção, os mecanismos de transmissão tendem a operar de forma menos eficiente, do que suposto pelos modelos padrões para os períodos de normalidade. Como exemplo, é observado que as "restrictive mortgage underwriting standards have reduced the effects of lower mortgage rates" (BERNANKE, 2012b, p. 8).

A incorporação dessas medidas pela revisão do NCM, em períodos de exceção, decorre da observação da crise atual na qual a ruptura financeira evidenciada em determinados mercados de crédito exigiu que a atuação do BC fosse direcionada a segmentos específicos. Nessa situação, a taxa de juros é suposta afetar a economia como um todo e não promove alterações desejadas nos segmentos específicos, quando da ocorrência de falhas de mercado. Ademais, os choques negativos na economia são combatidos por meio da redução da taxa de juros cujo limite inferior é igual a zero, sendo que nessa situação a PM convencional perde totalmente a sua operacionalidade (MISHKIN, 2012). Segundo Bernanke (2012b, p. 14): “At the same time, the costs of nontraditional policies, when considered carefully, appear manageable, implying that we should not rule out the further use of such policies if economic conditions warrant". Borio e Disyatat (2009, p. 26) também afirmam que: "These costs suggest that unconventional monetary policies should best be seen as special tools for special circumstances".

De outro modo, as justificativas para a retirada das PMNC e retomada da PMC é mais bem ponderada, a partir da discussão de cada uma delas. Nesse contexto, a revisão do NCM buscou analisar as implicações da armadilha da liquidez, que exigiu dos BCs ao redor do mundo a utilização de PMNC, representadas pelas políticas de gestão de quase débito, subdivididas em medidas 
de flexibilização de metas $^{12}$ e de flexibilização quantitativa ${ }^{13}$, políticas de crédito representadas pelas novas ferramentas de provisão de liquidez ${ }^{14}$, políticas de reservas bancárias e políticas de câmbio (BLANCHARD et al., 2010; MISHKIN, 2012; BÓRIO; DISYATAT, 2009).

\subsection{Políticas de quase débito}

Os questionamentos em relação às medidas de gestão de quase dívida, tanto em períodos normais quanto em período de exceção envolvem pelo menos a análise de quatro questões, a saber: i) a sua efetividade depende do contexto econômico; ii) as medidas não convencionais tem impactos não desejados sobre os níveis de preços; iii) os estudos empíricos que avaliam o efeito dessas políticas apresentam resultados mistos em relação a sua eficácia; e iv) os custos dessas medidas superam os benefícios ${ }^{15}$ em períodos normais. Cada uma das questões apresentadas é avaliada a seguir.

No que se refere à inter-relação entre políticas de gestão de quase dívida e contexto macroeconômico, observa-se que as economias com características estruturais de grande segmentação do mercado financeiro exibem, em períodos de ruptura financeira, uma tendência de redução da substitutibilidade entre os diversos ativos que são negociados nos mercados financeiros. Nessas economias, é suposto que a capacidade do BC afetar os preços de ativos é maior em períodos de crise se comparado aos períodos normais em que a taxa de juros de curto prazo e a arbitragem na curva de rendimentos operam de forma mais eficiente (BLANCHARD et al., 2010).

Um segundo ponto, referente à expansão quantitativa, é o efeito inflacionário que esta pode gerar, na medida em que a magnitude da expansão do balanço do BC afeta por si só a base monetária, a compra de títulos de longo prazo pode criar a percepção de que o $\mathrm{BC}$ está disposto à monetização a dívida pública, além das

\footnotetext{
${ }^{12}$ Aquisição de ativos financeiros específicos pelo BC sem impacto sobre a base monetária.

${ }^{13}$ Operações de compra de ativos com recurso do BC que não são esterilizadas e promovem ampliação da base monetária.

${ }^{14}$ Basicamente medidas associadas à janela de redescontos e empréstimos realizados pelo BC.

${ }^{15}$ Segundo Bernanke (2012b, p. 11): "The potential benefit of policy action, of course, is the possibility of better economic outcomes -- outcomes more consistent with the FOMC's dual mandate. In light of the evidence I discussed, it appears reasonable to conclude that nontraditional policy tools have been and can continue to be effective in providing financial accommodation, though we are less certain about the magnitude and persistence of these effects than we are about those of more-traditional policies".
} 
expectativas e da confiança dos agentes que incorporam uma elevação futura dos níveis de preços (MISHKIN, 2012; BERNANKE, 2012b). Nesse debate, Taylor (2010) vem argumentando que a expansão, sem precedentes, do balancete do FED reduziu significativamente a credibilidade e a independência ${ }^{16}$ do BC. Soma-se ao fato que a recuperação da atividade econômica concomitantemente a um quadro de elevado endividamento público, em virtude das políticas fiscais expansionistas, tende a promover pressões inflacionárias adicionais.

Os estudos empíricos, segundo Bernanke (2012b), apontam para resultados favoráveis aos impactos das políticas de gestão de quase débito, particularmente para reverter o processo deflacionário, embora a sua capacidade em afetar as taxas de juros de longo prazo e a melhoria das condições financeiras mais gerais seja um ponto controverso. Segundo o autor, as maiores dificuldades dos estudos que tentam avaliar os efeitos das políticas não convencionais referem-se ao problema de estimar a situação contrafactual. Esta não pode ser observada de forma direta, pois prescinde da avaliação de como a economia teria se comportado, na ausência das medidas de flexibilização de metas e quantitativa. Por outro lado, Woodford (2012), questionou a eficiências dessas medidas, alegando que grande parte da oferta de moeda foi absorvida enquanto reserva voluntária pelos bancos sem impacto significativo sobre o crédito.

Deve-se ressaltar ainda que os custos das políticas de gestão de quase débito podem ser representados pelo impacto destas sobre o funcionamento dos mercados de títulos, na medida em que o volume de compras do BC pode absorver uma parcela significativa desses ativos, gerando uma queda no volume de negociações destes mercados, impactando sobre os preços e liquidez. Um segundo ponto referese ao canal de assunção ao risco e os seus impactos sobre a estabilidade financeira. Um último argumento identifica os riscos de perda financeira no qual o BC está exposto, particularmente ao risco de taxa de juros, mas também a risco de crédito, no caso de títulos privados (BERNANKE, 2012b; MISHKIN, 2012). Desse modo, Bernanke (2012b, p. 14) afirma que:

\footnotetext{
${ }^{16}$ Nesse ponto, Blinder (2010, p. 21) aponta que as decisões de estímulo do FED, ao invocar a "Section 13(3) of the Federal Reserve Act", permitiu que este tivesse grandes poderes, ou seja, forte independência, sem a necessidade de aprovação das medidas pelo congresso ou pelo tesouro nacional. "But the broader question is this: How far beyond conventional monetary policy should the doctrine of central bank independence be extended? Remember, the Federal Reserve has never had nearly as much independence in the sphere of bank supervision and regulation, where it shares power with three other federal banking agencies, as it has in monetary policy (BLINDER, 2010, p. 21).
} 
(...) both the benefits and costs of nontraditional monetary policies are uncertain; in all likelihood, they will also vary over time, depending on factors such as the state of the economy and financial markets and the extent of prior Federal Reserve asset purchases. Moreover, nontraditional policies have potential costs that may be less relevant for traditional policies. For these reasons, the hurdle for using nontraditional policies should be higher than for traditional policies. At the same time, the costs of nontraditional policies, when considered carefully, appear manageable, implying that we should not rule out the further use of such policies if economic conditions warrant.

Nesse ponto, vem sendo reforçado conjuntamente com a política de gestão de quase débito, o apoio a forward policy guidance, anúncio sobre a intenção do $\mathrm{BC}$ em relação à tendência da taxa de juros ao longo de um dado período (BLANCHARD, 2013). As políticas de sinalização tornaram-se uma meta intermediária da PM convencional e tiveram forte apoio da revisão do NCM como um importante instrumento das PMNC para lidar com situações de ruptura financeira. Ressalta-se, no entanto, que as evidências empíricas sobre esse canal apoiam a sua efetividade, porém a magnitude de seus efeitos é controversa. Em síntese, as duas políticas, segundo Yellen (2011, p. 11):

In conclusion, I believe that both forward guidance and large-scale asset purchases have been effective tools for providing additional monetary accommodation under circumstances in which conventional monetary policy has been constrained by the zero-lower bound on the federal funds rate.

\subsection{Políticas de sinalização}

A política de sinalização (gestão de expectativas) proposta por Eggertsson e Woodford (2003) foi questionada por Williams (2011), que argumentou que a orientação para frente é inconsistente temporalmente. Tal fato se deve ao compromisso do $\mathrm{BC}$ de manter a taxa de juros de curto prazo, inferiores ao que faria no futuro, permitindo uma inflação mais elevada no futuro. No entanto, o BC poderia descumprir o compromisso assumido e elevar as taxas de juros para conter a elevação da taxa de inflação. Como resultado, a inconsistência temporal poderia afetar negativamente as expectativas e gerar impactos negativos sobre a credibilidade do BC.

Nesse ponto, Bernanke (2012b) e Yellen (2011a) concordam com o argumento, identificando que a política de orientação para frente, quando conduzida de forma incondicional, terá como consequência a inconsistência 
temporal. No entanto, segundo os autores, para evitar esse problema, a PM deverá ser condicional ${ }^{17}$ (discricionariedade restrita), de modo que a comunicação do BC com o público deve explicitar que a condução da PM, em relação às taxas de juros, depende das condições econômicas, podendo ser modificada, na medida em que estas condições se alteram.

Contudo, Clarida (2010) questionou o argumento em defesa de uma política condicional, alegando que esse tipo de comunicação pode ser percebido pelo público como uma política discricionária, comprometendo a ancoragem da inflação no futuro. Como alternativa, Woodford (2012) apresentou uma proposta ${ }^{18}$ de meta de PIB nominal, calculado pela multiplicação do hiato do produto e de uma meta de inflação (estipulada pelo BC). Neste, a revisão do cálculo do critério objetivo buscou a construção de um índice de referência mais simples, de modo a facilitar a comunicação do BC e o entendimento do púbico, objetivando reduzir os riscos de perda de credibilidade e compromisso da autoridade monetária.

Um segundo argumento, apresentado por Williams (2011), refere-se à possibilidade de que as expectativas dos agentes divirjam sobre o comportamento futuro do BC, afetando a eficácia da PM. A dificuldade de comunicação ocorre principalmente em períodos de crise, em que são acionados diversos instrumentos de PM, em grande medida não convencionais, ao mesmo tempo em que cada um destes dependerá de um conjunto de fatores e avaliações de risco por parte do BC. Desse modo, pode-se gerar uma compreensão imperfeita por parte dos agentes em relação aos objetivos da $\mathrm{PM}$ e consequentemente o BC poderá não conseguir influenciar as expectativas de mercado.

No entanto, apesar dos questionamentos, Bernanke (2009, 2012b), Yellen (2011a) e Willians (2011) argumentam que os estudos realizados pelo FED, para os primeiros anos da crise, têm demonstrado que o signalling channel constitui-se em um instrumento de PM especialmente importante e eficiente. A comunicação do BC com o público, sobre as suas intenções futuras de taxa de juros de curto prazo, bem como em relação a outras medidas, influencia as expectativas dos

\footnotetext{
${ }^{17}$ Segundo Woodford (2012), o compromisso condicionado deveria ter um critério objetivo que funcionasse como uma referência para a PM, permitindo uma comunicação clara com público. $\mathrm{O}$ autor sugere uma taxa de PIB nominal que utiliza como referência uma meta de inflação e o crescimento da taxa de crescimento do PIB potencial.

${ }^{18}$ Segundo Woodford (2012), a proposta de uma meta de PIB nominal e mais simples permite um entendimento melhor por parte do público, se comparado a regra proposta por Eggertsson e Woodford (2003).
} 
agentes. Esta, por sua vez, influencia as taxas futuras de curto prazo que determina a taxas de juros de longo prazo, por meio da hipótese de expectativas da estrutura a termo, promovendo alterações na demanda agregada e consequentemente no produto. Segundo Willians (2011 p. 4):

\begin{abstract}
Of course, we at the Fed have our own recent case study that speaks to the effectiveness of forward guidance. The Federal Open Market Committee's statement issued following our August meeting said, "The Committee currently anticipates that economic conditions including low rates of resource utilization and a subdued outlook for inflation over the medium run - are likely to warrant exceptionally low levels for the federal funds rate at least through mid-2013." (...) two-year Treasury yields fell by about 10 basis points and ten-year Treasury yields fell by about 20 basis points following the announcement. This provides prima facie evidence of the powerful effects of forward guidance at the zero bound.
\end{abstract}

Deve-se ressaltar ainda que a experiência japonesa da década de 2000 representou um ponto de referência para o debate em torno da eficácia das políticas de orientação para frente da PM. Segundo Blinder (2010), uma vez que o Japão também adotou medidas de expansão quantitativas, os resultados são favoráveis ao canal de sinalização, mas a magnitude de seus efeitos permanece controversa. Por outro lado, Willians (2011) identifica que alguns trabalhos empíricos ${ }^{19}$, para a crise atual, têm questionado a relevância e superioridade desse canal em relação aos outros. Ademais, como abordado por Cecioni et al. (2012), a orientação para a frente da PM pode gerar problemas associados a risco moral, bem como estimular comportamentos de risco, como enfatizado pelo canal de assunção ao risco.

Ademais o canal de sinalização está diretamente relacionado ao canal de balanço, na medida em que a utilização deste último aponta para as intenções da autoridade monetária em promover alterações em mercados específicos, tais como monetários, de títulos públicos e de agências governamentais, de câmbio, interbancário, dentre outros. Como resultado de tais medidas, a melhora nas expectativas de mercado tende a promover a redução de incertezas, prêmio de risco, taxas de juros, contribuindo para os efeitos esperados pelo $\mathrm{BC}$ nos mercados financeiros e na economia.

\footnotetext{
${ }^{19}$ Gagnon et al. (2011), Joyce et al. (2011), Swanson (2011), Krishnamurthy e Vissing-Jorgensen (2011), Wright (2011) e Neely (2011).
} 
Segundo Borio e Disyatat (2009, p. 13): "For example, the announcement that the central bank is prepared to engage in operations involving illiquid assets may in itself boost investor confidence in those assets, thereby reducing liquidity premia and stimulating trading activity". Segundo Mishkin (2012, p. 30):

Large-scale asset purchases may have an important role in managing expectations. An announcement of a policy commitment to manage expectations may not be sufficiently credible because talk is cheap. As we have seen, large-scale asset purchases are imposed costs on a central bank and so combining the announcement of the policy commitment with large-scale asset purchases may make the policy commitment more credible because the central bank has in effect put its money where its mouth is.

Finalmente, o canal de sinalização é um instrumento de PM mais eficiente em condições normais de mercado, uma vez que a operacionalização da PM em um RMI envolve diretamente a determinação da taxa de juros de curto prazo, na qual o BC detém monopólio sobre a base monetária. Por outro lado, quando o BC se utiliza de PMNC ele não é capaz de determinar, mas somente influenciar as mudanças de portfólio dos agentes, o que torna a efetividade dessas políticas no mínimo duvidosas, afetando negativamente o canal de sinalização (BORIO; DISYATAT, 2009).

\subsection{Políticas de reservas bancárias}

As Políticas de Reservas Bancárias desempenharam um papel importante nas discussões acerca das políticas não convencionais e tiveram destaque a partir da crise de 2007, embora nos países desenvolvidos tenha sido introduzida, enquanto exigências obrigatórias, apenas no Reino Unido, ao passo que nos demais países, observou-se a sua ampla expansão, porém como depósitos voluntários no BC. Por outro lado, a manipulação do percentual de reservas bancárias e sua alteração pelo BC para prover liquidez ao mercado bancário permaneceu enquanto um importante instrumento de PM em algumas economias emergentes ${ }^{20}$ e foram utilizadas no episódio recente da crise.

\footnotetext{
${ }^{20}$ Herrera (2010) analisa a utilização de exigência de reservas para a Colômbia, enquanto Montoro e Moreno (2011) avaliam os seus efeitos para o Brasil, Peru e Colômbia. Os resultados econométricos são favoráveis a utilização de reservas em um RMI, bem como foram importantes para o provimento de liquidez durante a crise de 2007.
} 
Nas economias desenvolvidas, tem-se observado que o efeito das políticas de expansão de RBs, bem como as medidas direcionadas ao setor privado não bancário, promoverá uma expansão agregada de moeda nas instituições depositárias, em parte pela ampliação do volume de depósitos bancários. No entanto, essa estratégia tem-se mostrado ineficiente, uma vez que o montante de recursos financiados direta ou indiretamente (depósitos) aos bancos permaneceu depositado na conta de reserva dessas instituições no BC (BÓRIO; DISYATAT, 2009).

As funções de PMNC atribuída as RBs sugerem duas características principais desse instrumento, qual seja: a função de promover estabilidade e confiança do mercado nas instituições depositárias (medida prudencial) e a sua capacidade de estimular a oferta de crédito bancário (medida de controle monetário). Segundo Borio e Disyatat (2009) e Gray (2011), essas funções são importantes em períodos de crise financeiras, mas apenas a gestão de liquidez é eficiente em períodos normais. Segundo Gray (2011, p. 9), "the uses of RR to support prudential requirements and monetary control is largely outdated, and can be more effectively met, in most cases, by use of other tools. But in some markets, in some circumstances, active use of RR may make sense".

Em relação à função prudencial, destacam-se algumas das questões do debate em torno da eficiência e substitutibilidade das RBs. Os benefícios, em períodos de ruptura financeira, estendem-se ao setor bancário e ao BC. Em relação ao primeiro, as RBs são o único meio aceito para a liquidação das transações (sem substitutos próximos). No segundo caso, as RBs permitem que o BC financie a sua política de balanço, sem a necessidade de emissão monetária ou títulos próprios, contribuindo para a estabilidade ${ }^{21}$ do sistema financeiro. A sua desvantagem, em períodos normais, refere-se ao fato de que os componentes do passivo do balanço do BC (títulos de curto prazo emitidos pelo BC e Tesouro e títulos de longo prazo emitidos pelo Tesouro) tornam-se novamente substitutos próximos. Ademais, a necessidade de o BC operar as políticas de balanço, dada a presença de fricções financeiras que tornam os diversos ativos substitutos imperfeitos, tendem a se normalizar e passa a ser novamente operada pelos mercados financeiros.

\footnotetext{
${ }^{21}$ Segundo Borio e Disyatat (2009): "This appears to be one of the main considerations behind the Bank of Japan's policy of expanding bank reserves under its quantitative easing policy during 2001-06 (Shirakawa (2009), Baba et al. (2005).
} 
No que se refere a sua função de controle monetário, normalmente as atribuições referem-se ao multiplicador monetário ${ }^{22}$ (restringir o balanço dos bancos comerciais) e o seu efeito sobre os spreads de taxa de juros (impacto sobre agregados e inflação). De outro modo, as desvantagens na utilização de RB podem ser sintetizadas em três pontos: i) as exigências de reservas representam uma forma de tributação, especificamente quando estas não são remuneradas ou a remuneração é inferior à taxa de juros overnight; ii) as RB são avaliadas como medidas imprecisas de PM, em virtude de sua variabilidade e dos efeitos das inovações financeiras, além de permanecerem inalteradas, por períodos significativos, na grande maioria dos países; iii) o seu impacto pode ser limitado, dado que esta pode estimular um processo de desintermediação do setor bancário em virtude da tributação e dos custos, estimulando outras alternativas (GRAY, 2011).

\subsection{Políticas de crédito}

As políticas de crédito, em períodos normais correspondem a função do $\mathrm{BC}$ enquanto emprestador de última instância, provendo empréstimos de liquidez às instituições depositárias, de modo a garantir o pleno funcionamento do sistema de pagamentos, bem como a confiança do público no sistema bancário. Normalmente essa política é operada por meio do redesconto, na qual as instituições com problemas de liquidez recorrem a empréstimos do BC a uma taxa punitiva, normalmente acima do valor cobrado pelo mercado, de modo a desestimular o risco moral.

No entanto, desde a crise financeira de 2007, essa política tornou-se a principal medida adotada pelas autoridades monetárias, exigindo um volume elevado de empréstimos e taxas de juros muito baixas, que combinado com as políticas de gestão de quase débito, promoveram uma expansão sem precedentes no balancete de diversos BCs, em particular no FED. Ademais, em virtude da dimensão da crise, essa medida de apoio à liquidez foi estendida a instituições não depositárias, bem como promoveu a compra direta e indireta (aceite de ativos como garantias) de ativos em diversos mercados (BLANCHARD et al., 2010).

\footnotetext{
22 Segundo Borio e Disyatat (2009, p. 19): “A striking recent illustration of the tenuous link between excess reserves and bank lending is the experience during the Bank of Japan's "quantitative easing" policy in 2001-2006. Despite significant expansions in excess reserve balances, and the associated increase in base money, during the zero-interest rate policy, lending in the Japanese banking system did not increase robustly".
} 
A crítica à utilização desse instrumento, em períodos normais, refere-se ao argumento de que a saída de investidores privados pode representar a preocupação destes em relação ao risco de solvência. Desse modo, a compra desses ativos, pelo $\mathrm{BC}$, poderá repercutir em aumento do risco do seu balanço, bem como estimular a aquisição privada desses ativos, promovendo a assunção de risco. Uma segunda crítica aponta para o risco moral, no qual a existência de emprestador de última instância poderá induzir a composição de carteiras com ativos de prazo mais longos e menos líquidos. Segundo Goodfriend (2013, p. 5):

Expansive credit initiatives undermine the Fed's legitimacy and potentially its capacity to pursue stabilization policy effectively. Moreover, expansive independent credit policy that bypasses the legislative process for whatever reason creates complexity and opacity that favors insiders and weakens the public's confidence in government and the rule of law.

Ressalta-se, ainda, que os questionamentos ao fornecimento de liquidez às instituições não depositárias, que normalmente não são supervisionadas e nem regulamentadas pelo $\mathrm{BC}$, referem-se à falta de informação da autoridade monetária sobre a situação financeira dessas instituições, quer seja sobre as condições de insolvência ou de iliquidez, bem como o auxílio de liquidez pode estimular o risco moral (BERNANKE, 2012a).

Por outro lado, Blanchard et al. (2013) argumenta que a provisão de liquidez, mesmo em tempos normais, deve permanecer como um instrumento para lidar com problemas de liquidez em mercados específicos. As críticas, segundo o autor, podem ser parcialmente resolvidas por meio da utilização de taxas de seguro (insurance fees), como um apoio indireto, e redesconto (haircuts), em vez de compras diretas. Ademais, o risco de crédito também deverá ser mitigado por meio de política de regulação e supervisão.

Finalmente, Mishkin (2012) aponta para a efetividade dessas medidas no reestabelecimento da liquidez dos mercados financeiros e promoção da estabilidade do produto e dos preços dos ativos, por meio de programas promoveram a queda da taxa de juros, prêmios de risco e estimularam a oferta de empréstimos. No entanto, como abordado pelo autor, as evidências empíricas que tentaram mensurar os efeitos das diversas políticas de crédito adotadas, por exemplo, nos EUA, encontram resultados mistos, desde a inexistência de efeitos 
de determinados programas, no mercado de crédito, até resultados favoráveis a efetividade dessas medidas na estabilização dos mercados financeiros.

\subsection{Políticas de câmbio}

A crise financeira de 2007 promoveu forte volatilidade no fluxo de capitais nas economias em desenvolvimento, particularmente naquelas caracterizadas pela abertura da conta de capitais, atividade econômica menos diversificada e mercados financeiros menos densos. Nestes, os efeitos observados, tanto em relação a estabilidade dos mercados financeiros quanto na variação e volatilidade do câmbio, foram mais desestabilizadores do que notado nas economias desenvolvidas $^{23}$. Tal situação reacendeu um antigo debate, em torna das políticas cambiais, bem como a eficiência dos instrumentos de intervenção sobre o câmbio e o controle dos fluxos de capitais (BLANCHARD, 2013). Segundo Borio e Disyatat (2009, p. 11):

exchange rate policy has been undertaken in a number of emerging market countries. This was done partly to counter abrupt reversals of capital inflows and the subsequent downward pressure on the exchange rate (for example, Brazil, Hungary and Mexico). In addition, the Swiss National Bank set out a policy of intervening in the foreign exchange market to contain upward pressure on the Swiss franc, as part of its efforts to reduce deflationary risks and loosen monetary conditions.

Até a ocorrência da crise, os países desenvolvidos que adotaram o RMI, utilizavam-se de um regime de câmbio flexível e a política cambial só importava na medida em que comprometesse a meta de inflação. Nestes, as variações na taxa de câmbio nominal, que promovessem desvalorização da moeda nacional, impactavam sobre o nível de preços e, desse modo, tornavam-se motivo de preocupação pelo BC. No entanto, nos países que apresentam mercados financeiros integrados, os instrumentos cambiais, tais como as intervenções esterilizadas do BC, não são eficientes, pois os fluxos de capitais tendem a reagir aos diferenciais de taxa de juros (BLANCHARD et al., 2013).

Por outro lado, esta não era uma realidade de diversos países emergentes, cujas variações cambiais, decorrentes da volatilidade dos fluxos de capitais,

\footnotetext{
${ }^{23}$ Segundo Blanchard et al. (2013): “(...) although the flow reversals within the euro area and the drying out of dollar liquidity in the European banking system during the early stages of the crisis are a reminder that vulnerabilities exist there as well (...)".
} 
promovem impactos não desejados sobre estabilidade financeira $\mathrm{e}$ macroeconômica. Dessa forma, a taxa de câmbio foi, de algum modo, gerenciada pelos BCs que, em determinados períodos, recorriam a intervenção no mercado cambial (compra ou venda de moeda e contratos de swap), tendo se intensificado durante a crise de 2007 (BLANCHARD et al., 2010). Nessa perspectiva, De Gregorio (2011, p. 94) argumenta que:

la validez de las herramientas alternativas para hacer frente a una entrada insostenible de capital puede ser de particular importancia cuando la preocupación por la volatilidad del tipo de câmbio real es relativamente alta. Por ejemplo, en las economías basadas en sus exportaciones cuyos mercados financieros presentan un desarrollo imperfecto, las fluctuaciones cambiarias y episodios persistentes de apreciación pueden causar un daño sostenido a la estructura productiva. En tales situaciones, una intervención cambiaria limitada y bien dirigida puede ayudar a aliviar las presiones transitorias y al mismo tiempo acumular reservas internacionales, que actúan como ahorro precautorio y autoseguro frente a las potenciales consecuencias de una salida repentina de capitales.

No entanto, Ostry et al. (2012) argumentam que essas medidas podem comprometer a credibilidade e transparência da PM, a não ser que os BCs reconheçam publicamente que a estabilidade da taxa de câmbio compõe a sua função objetiva de maximizar o "bem-estar". Desse modo, os autores defendem que as economias emergentes incorporem a meta de taxa de câmbio real e o instrumento de intervenção cambial, enquanto um segundo componente de um RMI, para lidar com os efeitos adversos do fluxo de capitais sobre a estabilidade macro e financeira. Dessa forma, variações significativas em relação ao fluxo de capitais poderiam ser compensadas pela mudança da taxa de juros de curto prazo, além da intervenção esterilizada do BC no mercado de câmbio doméstico. De modo a não comprometer a credibilidade e transparência da PM, esse segundo instrumento deverá estar subordinado a meta de inflação. Segundo OSTRY et al. (2012):

In response, for instance, to a destabilizing increase in capital inflows, the central bank can both lower the policy rate and intervene in the FX market to limit appreciation, in much the same way as it would do under unconstrained full discretion, but while avoiding the inflationary bias that would otherwise result from discretionary policies. Far from being reticent to use the second instrument, central banks should embrace its use as being fully consistent with the IT framework. 
Ressalta-se ainda que as intervenções esterilizadas, enquanto uma política de balanço que opera pelo canal de taxa de câmbio apresenta limitações similares às outras políticas de balanço, na medida em que a autoridade monetária opera com uma outra moeda, na qual não tem monopólio, e desse modo, depende do volume de reservas adquirida, além do fato de que tais medidas não determinam as alterações de portfólio dos agentes, apenas induz. Ademais, tais medidas representam um risco câmbio e que é incorporado ao balancete do $\mathrm{BC}$, além dos efeitos que a intervenção cambial pode gerar no canal de assunção ao risco (BLANCHARD, 2010; BÓRIO; DISYATAT, 2009).

Outro questionamento, apresentado por Ostry et al. (2012), refere-se aos impactos das intervenções cambais nos termos de troca entre os países, podendo gerar conflitos multilaterais, na medida em que esta pode ser interpretada como uma política de promoção de vantagem comparativa. Ademais, é discutida a capacidade da autoridade monetária identificar a apreciação que é gerada por mudanças nos fundamentos em detrimento das oscilações temporárias.

Uma questão complementar a esse debate analisa a adequação da utilização de controle de capitais. Conforme abordado por De Gregorio (2011), o Fundo Monetário Internacional, vem apoiando, ainda que em períodos de excepcionalidade, as medidas prudenciais, sustentando esse debate em uma literatura empírica cujos resultados têm apontado para uma eficácia parcial de sua utilização.

Na perspectiva defendida pelo Fundo Monetário Internacional, Blanchard et al. (2010) identificam que a utilização de medidas de controle de capitais, em períodos excepcionais, pode ser operada, por meio de controle sobre o conjunto de contratos nominados em moeda estrangeira em uma dada economia. Por outro lado, Eichengreen et al. (2010) defendem que esta deve compor o conjunto das políticas macroprudenciais na medida em que o controle de fluxos de capitais tem forte impacto sobre a estabilidade financeira e o nível de preços domésticos. Tal fato decorre da limitação da PM conter uma expansão de crédito, uma vez que a ausência de controles de capitais pode resultar da substituição de crédito doméstico por crédito internacional.

Ressalta-se, finalmente, as implicações em relação à coordenação dos objetivos das políticas financeiras e cambiais, que ao operar de modo a restringir o nível excessivo da exposição de residentes a contratos nominados em moeda estrangeira, promovem uma maior liberdade em relação as variações cambiais. No 
entanto, como enfatizado pelo canal de assunção ao risco, uma taxa de câmbio mais estável pode incentivar uma ampliação dos contratos em moeda estrangeira (BLANCHARD et al., 2010).

\section{Considerações finais}

A partir da discussão precedente, pode-se dizer que os períodos de normalidade, até a ocorrência da crise financeira de 2007/08, eram identificados como as situações nas quais os mercados operavam de forma eficiente, embora a rigidez de preços e salários fossem uma falha de mercado, dando a possibilidade de manipulação da demanda agregada no curto prazo pela PM. Por outro lado, a ocorrência de fricções financeiras entre os agentes era suposta como inexistente ou pouco significativa, em termos de impactos macroeconômicos. Nesse contexto, as PMC deveriam reduzir a volatilidade da inflação e com isso reduziriam a volatilidade do produto, tornado mais suave o caminho em direção a taxa natural de desemprego ("a grande moderação"). A operacionalidade dessa política se processava por meio do open-market (taxa de juros de curto prazo) e da comunicação que via a expectativa da estrutura a termo da taxa de juros afetava as taxas de juros de longo prazo, sem promover impactos relevantes nos preços de ativos, afetando a demanda agregada e a inflação almejada. Ressalta-se ainda que em uma situação de anomalia, ou seja, de taxa de juros próxima a zero, era suposto que o BC poderia afetar as taxas de juros de longo prazo por meio da orientação para a frente da PM.

Contudo, a crise recente demonstrou que durante um período de aparente estabilidade econômica emergia um processo de ampliação da alavancagem e da exposição ao risco nos mercados financeiros. Na contramão da suposta calmaria, se desenvolveu um forte movimento especulativo no mercado financeiro norteamericano, particularmente no mercado de hipotecas, cuja inter-relação com os demais gerou uma crise sistêmica com proporções similares a crise de 1929. Como resultado imediato, as PMNC foram necessárias e implantadas em grande magnitude para amenizar e reverter os impactos da ruptura financeira e da recessão na atividade economia. Senão de outra forma, a crise obrigou o NCM a rever algumas de suas hipóteses e proposições de política econômica, que desde o final da década de 2000 vem sendo cunha como Revisão do NCM. Embora esta não 
represente uma mudança significativa no paradigma desta corrente, alterou a ideia de normalidade/anormalidade econômica.

Desse modo, observou-se que as principais consequências da crise para a teoria e política econômica do NCM, foi a aceitação de que as fricções financeiras podem gerar resultados macroeconômicos significativos e indesejados. Como consequência, vem sendo defendido, por diversos revisores do NCM, a introdução de políticas financeiras ao escopo da PM para mitigar o risco de crises financeiras. A operacionalização da PM passa a incluir o canal de assunção ao risco e o gerenciamento de risco, além da manutenção do canal de juros por meio do openmarket e da comunicação. Permanece a estrutura a termo da taxa de juros, porém é acrescido o nível de alavancagem financeira, conectando, desse modo, a PM aos preços dos ativos. Essa nova configuração passa a representar as mudanças marginais que vem sendo debatidas, na medida em que a revisão do NCM identifica a necessidade de utilização de novos instrumentos e políticas parar mitigar a ocorrência de rupturas no comportamento dos agentes econômicos, bem como a utilização de ferramenta "não juros" para os períodos de exceção.

Já as políticas de balanço e sinalização, foram reafirmadas como PMNC, adequadas, apenas, para os períodos de anormalidade. Essas medidas tiveram no passado a sua sustentação teórica, em boa medida, referenciada em autores declaradamente críticos aos pressupostos absorvidos pelo NCM, tais como Tobin e Modigliani, no que se refere a ocorrência de fricções financeiras, a validade da estrutura a termo da taxa de juros e da hipótese de mercados eficientes. Senão de outro modo, essas medidas discricionárias foram combatidas pelos revisores do NCM, em boa medida, pelo risco que estas representam na reafirmação de pressupostos, como a neutralidade da moeda, inconsistência temporal e regra de Taylor. As PMNC tornam-se inadequadas para os períodos normais, mas eficientes para lidar com situações de crise (anormalidade), quando a taxa de juros se aproxima de zero. Desse modo, os períodos de anormalidade caracterizam-se pela ocorrência de fricções financeiras que geram impactos macroeconômicos relevantes, impossibilitando a identificação de padrões comportamentais.

\section{Referências}

ADRIAN, T.; KIMBROUGH, K.; MARCHIONI, D. The Federal Reserve's Commercial Paper Funding Facility. FRBNY Economic Policy Review, may, 2011. 
ANDO, A.; MODIGLIANI, F. The "life-cycle" hypothesis of saving: aggregate implications and tests. American Economic Review, v. 53, n. 1, p. 55-84, 1963.

BERNANKE, B.; BLINDER, A. Credit, money and aggregate demand. American Economic Review, v. 78, n. 2, p. 435-9, 1988.

BERNANKE, B.; GERTLER, M. Monetary policy and asset volatility. Federal Reserve Bank of Kansas City Economic Review, v. 84, n. 4, p. 17-52, 1999.

BERNANKE, B.; GERTLER, M. Should central banks respond to movements in asset prices? American Economic Review, v. 91, n. 2, p. 253-257, 2001.

BERNANKE, B. The crisis and the policy response. Stamp Lecture. Londres: London School of Economics, 2009.

BERNANKE, B. Some reflections on the crisis and the policy response. The Century Foundation Conference on "Rethinking Finance". Nova Iorque, 2012a.

BERNANKE, B. Monetary policy since the onset of the crisis. The Federal Reserve Bank the Kansas City Economic Symposium. Wyoming, 2012b.

BLANCHARD, O.; DELL'ARICCIA, M. Rethinking macroeconomic policy. Journal of Money, Credit and Banking, v. 42, n. 6, p. 199-215, 2010.

BLANCHARD, O; DELL'ARICCIA, M. Rethinking macro policy II: getting granular. IMF Staff Discussion Note, p. 199-215, 2013.

BLINDER, A. Quantitative easing: entrance and exit strategies. Working Paper $\mathrm{n}$. 204, 2010.

BORIO, C.; ZHU H. Capital regulation, risk-taking and monetary policy: a missing link in the transmission mechanism? BIS Working Papers n. 268, 2008.

BORIO, C.; DISYATAT, P. Unconventional monetary policies: Monetary Economic BIS WP 292, 2009.

CECIONI, M.; FERRERO, G.; SECCHI, A. Unconventional monetary policy in theory and in practice. Economic Outlook and Monetary Policy Research Department. Bank of Italy, 2011.

CLARIDA, R. What has - and has not-been learned about monetary policy in a low inflation environment? A Review of the 2000s. Columbia University, 2010. 
CLARIDA, R.; GALÍ, J.; GERTLER, M. The science of monetary policy: a new keynesian perspective. Journal of Economic Literature, v. XXXVII, p. 1661-1707, 1999.

DE GREGÓRIO, J. Los flujos de capital y la interacción entre la política macroprudencial y la política monetaria. Conferência Anual del Banco Central de Chile. Santiago, 2011.

EGGERTSSON, G.; WOODFORD, M. The zero bound on interest rates and optimal monetary policy. Brookings Papers on Economic Activity, 34, p. 139-211, 2003.

GOODFRIEND, M.; KING, R. The new neoclassical synthesis and the role of monetary policy. In: BERNANKE, B; ROTEMBERG, J. NBER Macroeconomics Annual, 1997.

GOODFRIEND, M. Monetary policy in the new neoclassical synthesis: primer. Economic Quarterly, Federal Reserve Bank of Richmond, v. 90/3, 2004.

GOODFRIEND, M. The monetary policy debate since October 1979: lessons for theory and practice. Federal Reserve Bank of St. Louis Review, n. 2, p. 243-262, 2005.

GOODFRIEND, M. Lessons learned from a century of federal reserve last resort lending. National Bureau of Economic Research, n. 11, 2013.

GRAY, S. Central bank balances and reserve requirements. IMF Working Paper, 11/36, 2011.

HERRERA, H.; BETANCOURT, Y.; VARELA, C.; RODRIGUEZ, R. Effects of reserve requirements in an inflation-targeting regime: the case of Colombia. BIS Working Papers, n. 54, 2010.

JOYCE, M.; LASAOSA, A.; STEVENS, I.; TONG M. The financial market impact of quantitative easing. Working Paper n. 393. Bank of England, 2010.

KUTTER, K. N.; MOSSER, P, C. The monetary transmission mechanism: some answers and further questions. FRBNY Economic Policy Review, 2002.

MC CALLUM, B. Recent developments in monetary policy analysis: the role of theory and evidence. NBER Working Paper, 7088, 1999.

MEYER. L. Does money matter? Federal Reserve Bank of St. Louis, 2001. 
MISHKIN, F. Symposium on the monetary transmission mechanism. Journal of Economic Perspectives, v. 9, n. 4, p. 3-10, 1995.

MISHKIN, F. Will monetary become more of a science? NBER Working Paper, n. $13566,2007$.

MISHKIN, F. S. Monetary policy flexibility, risk management, and financial disruptions. Journal of Asian Economics, n. 21, p. 242-246, 2010.

MISHKIN, F. Central banking after the crisis. 16th Annual Conference of the Central Bank of Chile. Santiago, 2012.

MODIGLIANI, F.; SUTCH, R. Innovations in interest-rate policy. American Economic Review, v. 56, n. 1, p. 178-197, 1966.

MONTORO, C.; MORENO, R. The use of reserve requirements as a policy instrument in Latin America. BIS Quarterly Review, mar. 2011.

OSTRY, J. ATISH, R.; CHAMON, M. Two Targets, Two instruments: monetary and exchange rate policies in emerging market economies. IMF Staff Discussion Note, 12/01, 2012.

ROMER, D. Keynesian macroeconomics without the LM curve. Journal of Economic Perspectives, v. 14, n. 2, p. 149-169, 2000.

TAYLOR, J. Discretion versus policy rules in practice. Carnegie-Rochester Conference Series on Public Policy, v. 39, n. 1, p. 195-214, 1993.

TAYLOR, J. The monetary transmission mechanism: an empirical framework. Journal of Economic Perspectives, v. 9, n. 4, p. 11-26, 1995.

TAYLOR, J. An exit rule for monetary policy. Unpublished manuscript. Stanford University, 2010.

TOBIN, J. A general equilibrium approach to monetary theory. Journal of Money Credit, and Banking, 1969.

WILLAMS, J. Unconventional monetary policy: lessons from the past three years. Swiss National Bank Research Conference. Zurich, 2011.

WOODFORD, M. Financial intermediation and macroeconomic analysis. Journal of Economic Perspectives, v. 24, n. 4, p. 21-44, 2010. 
WOODFORD, M. Inflation targeting and financial stability. Sveriges Riksbank Economic Review, 2012.

YELLEN, J. Unconventional monetary policy and central bank communications. University of Chicago Booth School of Business US Monetary Policy Forum. Nova Iorque, 2011a.

YELLEN, J. The Federal Reserve's Asset Purchase Program. Allied Social Science Associations Annual Meeting. Denver, 2011b. 